\title{
Reseña del libro Literatura y derivas semióticas, de Paula Aguilar [et al.]; compilado por
}

Aymará Cora De Llano. Ia ed.- Mar del Plata: Eudem, 2020.

\author{
Sabrina Gil \\ CONICET (Consejo Nacional de Investigaciones \\ Científicas y Técnicas de Argentina) \\ CELEHIS (Centro de Letras Hispanoamericanas) \\ UNMDP (Universidad Nacional de Mar del Plata, \\ Argentina)
}

El volumen Literatura y derivas semióticas, recientemente editado por EUDEM (editorial de la Universidad Nacional de Mar del Plata) es un signo de nuestra época. En principio, porque su publicación y su presentación pública llevan la marca de la pandemia y las medidas de distanciamiento y aislamiento social. Editado en formato PDF y con descarga gratuita, ${ }^{1}$ fue presentado mediante videoconferencia, lo que permitió una concurrencia internacional y, además, la producción de un texto audiovisual que dialoga con el escrito y puede ser visto y replicado en internet. ${ }^{2}$ A su vez, porque propone un abordaje de la literatura como objeto múltiple, irreductible a la mirada de un solo sujeto y, por tanto, asediada desde perspectivas disímiles, que enfocan aspectos heterogéneos, estallando la unidad de un corpus, una serie, una materialidad. Es, por ello, una sucesión de lecturas que no aspiran a la constitución de una textura lisa, sino y como orienta el título, al trazado de algunas de las posibles derivas del ejercicio literario.

1 Para descargar desde la página de EUDEM: http://www2.mdp.edu.ar/index.php/institucional/areasrectorado/secretaria-de-comunicacion-y-relaciones-publicas/eudem/libros-digitales-descarga-gratuita

2 Presentación: https://www.youtube.com/watch?v=goJBHuzz-VM\&ab_channel=UniversidadNaci onaldeMardelPlata 
El volumen recoge una selección y reformulación de trabajos presentados en los simposios que se llevaron adelante en el vi Congreso internacional del CELEHIS (Centro de Letras Hispanoamericanas, UNMDP), celebrado en Mar del Plata en noviembre de 20I7. Sale a la luz en el mismo mes en el que debería haberse realizado el vir encuentro, postergado por la situación sanitaria. De modo que el azar ha jugado a favor para que el libro reponga, en cierta manera, el espacio de encuentro e intercambio que suponen los congresos del CELEHIs. En este caso, a través de la producción de ocho investigadoras e investigadores del centro, nueve del resto de Argentina y tres internacionales (España y Brasil).

Los simposios estructuran el volumen en cinco secciones: «Formas de la memoria», "Literatura y artes», "El arte del diálogo. Comparativismo contrastivo», «Literatura y prensa», "Literatura, enseñanza, sociedad y mercado.» Ya los títulos indican una noción de literatura ampliada, expansiva, en interacción dinámica y porosa con el conjunto de las artes, el mercado, la prensa, la educación. Sobre ello, Aymará de Llano, directora del CELEHIS, reflexiona en la presentación: «la literatura siempre está presente en estas derivas que se entrelazan, enriquecen o interfieren mutuamente en juegos continuos de diferentes modalidades y en materiales múltiples, todos inmersos en la semiosis social» (o9).
La primera sección, «Formas de la memoria», es presentada por Mónica Marinone y Laura Scarano y recoge cuatro artículos. Estos se vinculan desde una concepción de la literatura y las artes como vías privilegiadas para la exploración y revisión de la memoria individual y colectiva. En palabras de las coordinadoras: «son modulaciones diversas donde la memoria se hace discurso trazando un arco desde la reconstrucción de la infancia individual, el trauma desolador de la pérdida familiar, la «memoria de sí» como factor determinante para la estabilización de la subjetividad, hasta la revisión del par historia/memoria en la narrativa, una tendencia de enorme peso en el contexto de la literatura en general» (II).

"Género y exilio: categorías de análisis para enfrentarse a una novela de Elena Fortún», de Raquel Arias Careaga (uAM-España) analiza en Oculto sendero el cuestionamiento de las identidades genéricas y sexuales desde la reflexión autobiográfica, de cara a la aceptación del yo marginal. En «Apontamentos sobre memória e história na narrativa brasileira», Pedro Brum (ufsm/Santa María- Brasil) parte de una consideración de Antonio Cándido sobre la escritura de Graciliano Ramos como conjunción de ficción y confesión para rastrear las proyecciones en la narrativa brasileña del siglo xx de una curva oscilante entre el tono autobiográfico y la conciencia de que la historia individual es corolario de 
la Historia colectiva. «Memoria y afecto en la narrativa argentina de Hijos (sobre Aparecida de Marta Dillon)» de Paula Aguilar (UADER) parte de las teorías de los afectos y la emotividad para la exploración de una poética afectiva de la memoria como vía de aproximación al pasado. La sección cierra con «Un yo $\sin$ yo. Memoria y subjetividad en Desarticulaciones de Sylvia Molloy» de Andrea Ostrov (UBA). Ostrov convoca la pregunta por la identidad ante la pérdida de la memoria y el lenguaje en la novela de Molloy y sostiene que en el relato del quiebre subjetivo de un ser querido, la narradora se enfrenta con la borradura de sí misma y plantea la paradoja del «ser ausente» (60), un quiebre entre ser y estar desarrollado en la progresiva ruptura de subjetividad y lenguaje.

Gabriela Tineo y Marcela Romano introducen la segunda sección del volumen, "Literatura y artes» que compila tres trabajos en los que la literatura se expande hacia la transposición, la intermedialidad y el cruce con otros lenguajes artísticos: cine, artes visuales y danza. Como perspectiva global sostienen que: «si bien estas convergencias e interacciones han atravesado la historia de la cultura, las nuevas condiciones de producción, circulación y consumo de los bienes simbólicos, propiciadas por la tecnología, las industrias culturales e Internet, alientan discusiones teóricas, críticas y metodológicas que demandan, en nuestros tiempos, tomas de posición dentro del campo académico» (63).

Carlos Dámaso Martínez (UNA/UBA) en "Antonio Di Benedetto: su afinidad con el cine y la transposición fílmica de Aballay" recorre textos de Di Benedetto en los que identifica un procedimiento de escritura afincado en la búsqueda de efectos cinematográficos, una forma de «pensar en imágenes» (65). En este marco, incorpora un análisis de las «relaciones intertextuales o transtextuales» (68) entre la película de Fernando Spiner, Aballay, el hombre sin miedo y el cuento "Aballay». Isabel Molinas (UNL) en "Literatura y artes visuales: relato e indisciplina en la obra de Abel Monasterolo» analiza el diálogo que el artista propone entre dos objetos intermediales, su cuaderno Rio das mortes, vira vermelho, donde literatura y pintura son cobijadas por un mismo cielo (76) y la novela de Luis Sagasti Bellas artes. La sección cierra con "Cruzar para crear. Entre literatura y danza. Un estudio interdisciplinario» de María Victoria Alcalá (UNA/ UBA) aborda la presencia corporal en la producción de Susana Thénon y de Iris Scaccheri para reflexionar sobre "cómo se enuncia el cuerpo tanto en la poesía como en la danza» (9I).

La tercera sección, «El arte del diálogo. Comparatismo contrastivo» es presentada por Liliana Swiderski y Francisco Aiello. Como sugiere el título, los cuatro trabajos que la componen se ubican en 
perspectivas comparativas orientadas al diálogo, la intertextualidad y la revisión de límites simbólicos y geográficos en la literatura. Como una demanda de la inscripción de la literatura en procesos contemporáneos que borran o acortan fronteras, asumen una matriz reticular que "hace hincapié en los puntos de articulación entre productos culturales, en la permeabilidad de sus límites y en la fecundidad de sus tensiones» (Io8).

En «Pensar la literatura como diálogo: hermenéutica y reflexión autopoética en Jeanette Winterson y Carmen Martín Gaite» María Estrella (UNMDP) selecciona autopoéticas de una escritora española y una británica para reflexionar sobre la noción de diálogo en la literatura a partir de la atención al intercambio, el encuentro y la conexión. Francisco Aiello (UNMDP) en "La migration des coeurs de Maryse Condé: consideraciones en torno de la reescritura» estudia otra modalidad del diálogo y la interconexión a partir de una revisión de los análisis críticos sobre la reescritura de Wuthering Heights de Emily Brontë que realiza Condé. Marcelo Topuzian (UbA-Untref) en "Una perspectiva alternativa para las literaturas peninsulares: los estudios ibéricos», se introduce en la discusión anticipada en el título, siguiendo los aportes de Joan Ramón Resina a la configuración de un objeto de estudio ibérico, que supere la segmentación lingüístico-cultural y el peso del hispanismo. La sección cierra con otro abordaje metacrítico: «De la picaresca al Bildungsroman: el abordaje de los géneros literarios en el comparatismo" Liliana Swiderski (UNMDP) pasa revista de apelaciones críticas a la picaresca para caracterizar el Bildungsroman en función de discutir la pertinencia y vigencia de la noción de género literario en los estudios comparados.

La sección «literatura y prensa», presentada por Rosalía Baltar y Mónica Scarano, aborda el cruce indicado en el título en un dilatado arco temporal que permite observar transformaciones en las modalidades de interacción y en los problemas elaborados por la crítica. La perspectiva que nuclea los cuatro artículos asume que «la interacción entre ambos espacios -no siempre disociados, a lo largo de su historia- afecta cuestiones nodales del hecho literario y de la cultura escrita, que involucran "cuestiones nodales del hecho literario y de la cultura escrita» e «involucran la historia, la ficción, el espacio público y la configuración de la opinión pública, la construcción de subjetividades y sus transformaciones, la representación, el discurso polémico, el campo intelectual y cultural y el ejercicio de la autoría, entre otros (I63).

Rosalía Baltar (UNMDP), en «El autor como lector en la Crónica científica y literaria (Madrid, I817- I820)", se detiene en este periódico y en la figura de su editor, José Joaquín de Mora. Sostiene que «la máquina proliferante de la prensa deci- 
monónica crea un sistema publicitario ecoico que no deja, sin embargo, de vislumbrar las formas de la censura» (I66). En «Antagonistas autorizados, tolerados y excluidos: la política editorial de $E l$ Argos de Buenos Aires frente a Francisco de Paula Castañeda» Virginia P. Forace (UNMDP) estudia las estrategias diferenciales del Argos... como periódico oficialista, en un momento de conflicto entre la prensa de combate y la de intercambio de ideas. Mónica E. Scarano (UNMdP) en «Del diario al libro: avatares en la edición de las crónicas rubendarianas» interroga la percepción de incomodidad en la relación entre literatura y prensa mediante un análisis del proceso de transposición de las crónicas urbanas de Rubén Darío publicadas en La Nación a la antología Todo al vuelo. Mariana Bonano (UNT) cierra la sección con «En torno al periodismo narrativo de Leila Guerriero y el ejercicio de la crónica» Indaga los textos de no ficción y las intervenciones ensayísticas de Guerreiro de cara a una lectura política de la crónica como producto de una mirada particular que interroga y desautomatiza los modos de narrar.

La última sección del volumen, presentada por Carola Hermida, se titula «Literatura, enseñanza, sociedad y mercado" y centra en interrogaciones sobre las fuerzas autónomas y heterónomas que se cruzan en el campo literario, en especial en relación con el mercado, las políticas editoriales y los lineamientos educativos. Los cuatro trabajos que componen la sección reflexionan «en torno a estos cruces y contaminaciones y acerca de las instituciones que ciñen, impulsan, promueven, presionan o subordinan el hacer literario (...). Así, dan cuenta de las estrategias mediante las cuales el mercado editorial, el campo literario, la escuela y/o las políticas educativas buscan incidir en estas decisiones, que son entonces simultáneamente económicas, ideológicas y culturales, y las tácticas de sumisión o rebeldía a las que dan lugar» (239).

El primer artículo, de Esteban Prado (UNMDP), se titula «De la reflexión sobre el valor literario de textos inéditos a la lectura de lo intangible e impublicable en los devenires artistas de Alberto Laiseca, Osvaldo Lamborghini y Héctor Libertella» Prado aborda el problema de la correlación entre valor literario y valor de mercado, a través de textos considerados impublicables y apelando a las categorías de valor cultural y actos de crédito. Soledad Sánchez Flores (Universidad de Granada- España) en «La resignificación del capital literario brasileño en España: editoriales y crítica» estudia la circulación y visibilidad de la literatura brasileña en Espańa a comienzos de este siglo, como resultado de políticas editoriales y culturales. Los dos últimos artículos centran en publicaciones educativas y editoriales orientadas a la educación. «Educación, mercado y literatura. El libro de texto como lugar de disputa» 
de Aldana Baigorri (UNLP) focaliza en volumen) con «Martín Fierro, edición dos propuestas editoriales para 5to año escolar. El caso GOLU» donde analiza (Estrada y Puerto de Palos) en diálogo transformaciones y continuidades de las con los diseños curriculares y los pactos ediciones de Martín Fierro en el catálodidácticos. En el mismo sentido, Carola go de Grandes Obras de la Literatura Hermida (UNMDP) cierra la sección (y el Universal de Kapelusz. 